IZA DP No. 9629

Working Hard in the Wrong Place:

A Mismatch-Based Explanation to the UK Productivity Puzzle

Christina Patterson

Ayșegül Șahin

Giorgio Topa

Giovanni L. Violante

January 2016 


\title{
Working Hard in the Wrong Place: A Mismatch-Based Explanation to the UK Productivity Puzzle
}

\author{
Christina Patterson
}

MIT

\author{
Ayşegül Şahin \\ Federal Reserve Bank of New York \\ Giorgio Topa
}

Federal Reserve Bank of New York and IZA

Giovanni L. Violante

New York University, CEPR, IZA and NBER

Discussion Paper No. 9629
January 2016

IZA

P.O. Box 7240

53072 Bonn

Germany

Phone: +49-228-3894-0

Fax: +49-228-3894-180

E-mail: iza@iza.org

Any opinions expressed here are those of the author(s) and not those of IZA. Research published in this series may include views on policy, but the institute itself takes no institutional policy positions. The IZA research network is committed to the IZA Guiding Principles of Research Integrity.

The Institute for the Study of Labor (IZA) in Bonn is a local and virtual international research center and a place of communication between science, politics and business. IZA is an independent nonprofit organization supported by Deutsche Post Foundation. The center is associated with the University of Bonn and offers a stimulating research environment through its international network, workshops and conferences, data service, project support, research visits and doctoral program. IZA engages in (i) original and internationally competitive research in all fields of labor economics, (ii) development of policy concepts, and (iii) dissemination of research results and concepts to the interested public.

IZA Discussion Papers often represent preliminary work and are circulated to encourage discussion. Citation of such a paper should account for its provisional character. A revised version may be available directly from the author. 
IZA Discussion Paper No. 9629

January 2016

\begin{abstract}
Working Hard in the Wrong Place: A Mismatch-Based Explanation to the UK Productivity Puzzle*

The UK experienced an unusually prolonged stagnation in labor productivity in the aftermath of the Great Recession. This paper analyzes the role of sectoral labor misallocation in accounting for this "productivity puzzle." If jobseekers disproportionately search for jobs in sectors where productivity is relatively low, hires are concentrated in the wrong sectors, and the post-recession recovery in aggregate productivity can be slow. Our calculations suggest that, quantified at the level of three-digit occupations, this mechanism can explain up to two thirds of the deviations from trend-growth in UK labor productivity since 2007.
\end{abstract}

JEL Classification: E24, E32, J24

Keywords: misallocation, productivity

Corresponding author:

Ayşegül Şahin

Federal Reserve Bank of New York

33 Liberty Street

New York, NY 11201

USA

E-mail: aysegul.sahin@ny.frb.org

\footnotetext{
"We are grateful to John Van Reenen, the Editors and an anonymous referee for their useful comments. The opinions expressed herein are those of the authors and not necessarily those of the Federal Reserve Bank of New York or the Federal Reserve System.
} 


\section{Introduction}

Since the onset of the Great Recession, UK labor productivity growth has been exceptionally weak. At the start of 2013, output per hour was more than 10 percentage points lower than it would have been if, after 2008, productivity had continued along its trend growth of 1.5 percent per year (Pessoa and Van Reenen, 2014, Figure 2). Official calculations from the Bank of England reach similar conclusions (Barnett et al., 2014, Chart 1).

While it is not uncommon for labor productivity to decline during downturns, the recent drop has been significantly larger and more prolonged than in any other post-war contractions. For example, six years after the start of each previous recession since the early 1970s, labor productivity was already between 10 and 20 percent higher than its pre-recession level (Barnett et al., 2014, Chart 2). Instead, in early 2013 aggregate labor productivity was still roughly 4 percent below its 2007 level. Because of its unusual magnitude and duration, this shortfall is referred to as the UK productivity puzzle.

Standard economic theory based on a constant returns to scale aggregate production function distinguishes three determinants of labor productivity: total factor productivity (TFP), capital deepening, and factor utilization. ${ }^{1}$ As documented by Pessoa and Van Reenen (2014, Figure 14), in TFP terms, the current recession is not so unusual compared with severe recessions of the past: TFP dropped by roughly 4 percent, but then it recovered quickly thereafter. Moreover, while capacity utilization fell significantly in 2009 , and could thus be the cause of the sudden drop of labor productivity at the onset of the recession, this explanation is less suited to account for its persistent stagnation and its severity relative to previous recessions. It is quite unlikely that firms would continue to keep their hold on idle workers five to six years after the end of the recession. Indeed, survey measures of capacity utilization were back to pre-recession long-term averages by 2011 in manufacturing, and two years later in services (see, again, Barnett et al., 2014, Chart 6).

The dynamics of the capital-labor ratio hold more promise. Pessoa and Van Reenen (2014, Figure 11) document that UK real investments, after collapsing by 25 percent during 2008, have remained 20 percentage points below their pre-recession level for the following five years. Their calculations suggest that capital shallowing can account for a large portion of the labor productivity drop. Their preferred explanation for the decline in the capital-labor ratio emphasizes greater wage flexibility. As shown by Gregg et al. (2014), real wages are

\footnotetext{
${ }^{1}$ We note that mismeasurement could be, potentially, important to the extent that investment in intangibles such as expenses on R\&D, intellectual property rights, and sales-based capital (e.g., brand names) are not properly captured by official statistics and are countercyclical. However, Barnett et al. (2014) survey the literature and conclude that these sources of output mismeasurement account for at most $1 / 4$ of the missing productivity growth.
} 
much more responsive to negative output shocks now than they have been in previous recessions, and this might have induced firms to substitute capital with cheaper labor services. In turn, Blundell et al. (2014) offer an explanation for the unusual dynamics of real wages that occurred in the Great Recession-a decline of 7 percent in four years, compared to a rise of 10 percent, over the same time span, following the downturn of 1990 (Blundell et al. 2014, Figure 4). They argue that the UK experienced a positive labor supply shock triggered by (i) changes in welfare policies that made work more attractive and tightened job-search conditions attached to the receipt of UI benefits, and (ii) an increase in statutory pension age for women that strengthened their labor force attachment.

The combination of a labor supply shock, downward pressure on a flexible wage structure, and labor-capital substitution to exploit cheaper labor inputs is, currently, the leading interpretation of the stagnation in labor productivity of the British economy. However, it is unclear whether, quantitatively, this rendition can fully account for the data. In this paper we offer an alternative, but largely complementary, explanation for the UK productivity puzzle. We deviate from the one-sector view of the production structure, and instead emphasize the role of labor misallocation across sectors of the economy. Specifically, we extend the methodology of Sahin, Song, Topa, and Violante (2014, hereafter SSTV)—developed to measure mismatch unemployment-to quantify the impact that this misallocation channel has on output and on labor productivity.

To understand the mechanism, consider an economy segmented along many sectors that are heterogeneous in their productivity. Each sector has its own frictional labor market, where the frictions are captured by a sector-specific matching function that takes vacancies (posted in that sector) and unemployed workers (searching in that sector) as inputs, and generates new hires (by firms operating in that sector). To measure sectoral mismatch, we compute the allocation of job seekers across sectors that would be chosen by an outputmaximizing planner constrained by the within-sector search frictions, and we compare it to the empirical allocation observed from the data. The gap between the two allocations implies a different sectoral distribution of hires, and therefore, of employment. It also implies a different level of aggregate output, since the planner will allocate job seekers in the sectors with the highest productivity, as long as vacancies are available and the matching frictions are not too severe. As a result, the planner's allocation generates a counterfactual path for aggregate labor productivity. By comparing this counterfactual time-series with the observed one, we can quantify the role of labor mismatch in accounting for productivity dynamics.

The bite of our explanation relies on the existence of gaps in productivity levels across sectors, not necessarily on the presence of differentials in productivity growth. Thus, even 
if the drop in labor productivity due to capital shallowing is common across all sectors of the economy, the mismatch channel can still contribute to the fall in observed total labor productivity through an adverse change in sectoral composition of employment. Clearly, differential rates of productivity growth can exacerbate the importance of the misallocation channel. Incidentally, Barnett et al. (2014, Chart 10) show that the standard deviation of productivity across industries doubled between 2008 and 2013, and we report similar evidence for occupations in Section 4.

It is useful to emphasize that our explanation is unrelated to the idea that labor productivity is low because the composition of the labor force has worsened. Indeed, Blundell et al. (2014) do not find support for this composition channel. In our model, the reduction in aggregate productivity does not occur because of changes in the pool of jobseekers, but because a disproportionate fraction of new hires occurs in the least productive sectors of the economy (we provide evidence of this pattern in Section 4).

Our formalizing of output loss from mismatch as "distance from a benchmark allocation" follows the same insights of the vast literature on misallocation and productivity (Restuccia and Rogerson, 2008; Hsieh and Klenow, 2009; Jones, 2013; Midrigan and Xu, 2014; Moll, 2014). The key difference is that we recognize that an essential feature of the labor reallocation process is that labor markets are frictional, and hence the benchmark allocation-chosen by a fictitious planner-must be constrained efficient. This means that the relevant data for our empirical exercise are not just disaggregated employment data, as in most of the misallocation literature, but sectoral-level information on unemployment, vacancies, and matching frictions. While the data requirements for the measurement exercise are more demanding, by using a less extreme benchmark that allows for deviations from competitive markets, the results are, in our opinion, more credible.

We quantify the importance of this misallocation channel by using UK data on vacancies, unemployment, and hires by disaggregated occupational group (2- and 3-digit) over the period 2006-2012. Our definition of sector is therefore an occupation. Our findings suggest that mismatch induced a reduction in both employment and output, and that this decline persisted through 2012. Combining the dynamics of output and employment, we find that occupational mismatch explains about two thirds of the deviations from trend-growth in UK labor productivity since 2007.

The remainder of the paper is organized as follows. We present our theoretical framework in Section 2. We describe the data used in the analysis in Section 3. Our empirical results and counterfactual exercises are reported in Section 4. Section 5 concludes the paper. 


\section{Theoretical framework}

In this section, we briefly describe the theoretical framework developed in SSTV to conceptualize the notion of mismatch unemployment, and explain how to generalize it to measure the size of output, employment, and productivity losses that can be attributed to mismatch between the distribution of labor demand (vacant positions) and the distribution of labor supply (job seekers) across sectors.

We envision the aggregate economy as comprising a large number of distinct labor markets, or sectors. Productivity is heterogenous across sectors and time varying. Each labor market is frictional, meaning that its hiring process is governed by a sector-specific matching function. We also allow the degree of matching efficiency to vary across sectors and over time. $^{2}$ To assess the existence of mismatch in the data, in the spirit of Mincer (1966) and Jackman and Roper (1987), we ask whether unemployed job seekers search for new jobs in the wrong sectors. Put differently, given the observed distribution of productive efficiency, matching efficiency, and vacancies across labor markets, are unemployed workers misallocated? Answering this question requires comparing the actual equilibrium allocation of unemployed workers across sectors to an ideal allocation. The ideal allocation that we choose as our benchmark is the one that would be selected by an output-maximizing social planner acting without impediments in shifting idle labor across sectors, but constrained by the within-market matching frictions that are summarized by the matching functions. We show that optimality for this planner dictates equating efficiency-weighted vacancy-unemployment ratios across sectors. Deviations from this allocation induce inefficiencies and may lead to output and productivity losses.

By manipulating the planner's optimality condition, we show how to construct an index measuring the fraction of output from new hires lost every period because of job seeker misallocation across sectors with different productivity. In turn, this index is then used to arrive at counterfactual measures of output, employment, and productivity in absence of mismatch. These counterfactuals allow us to assess the role of sectoral mismatch in accounting for the UK productivity puzzle. Intuitively, mismatch can induce a prolonged drop in aggregate productivity if, for a number years, new hires are disproportionately concentrated in the low productivity sectors. In Section 4, we show that this was indeed the case in the UK in the period 2007-2012.

\footnotetext{
${ }^{2}$ By matching efficiency we mean the number of hires produced by the matching function for given vacancies and unemployment, i.e., the TFP of the matching function.
} 


\subsection{Model}

Time is discrete and indexed by $t$. The economy is comprised of a large number $I$ of distinct labor markets (sectors) indexed by $i$. New production opportunities, corresponding to job vacancies $\left(v_{i t}\right)$, arise exogenously across sectors. ${ }^{3}$ The economy is populated by a measure one of risk-neutral individuals who can be employed in sector $i\left(e_{i t}\right)$, unemployed and searching in sector $i\left(u_{i t}\right)$, or out of the labor force. The aggregate labor force is $\ell_{t}=\sum_{i=1}^{I}\left(e_{i t}+u_{i t}\right) \leq 1$. On-the-job search is ruled out and an unemployed worker, in any given period, can search for vacancies in one sector only. We set the additional value of leisure for the non-employed individuals to zero—a normalization—but allow a disutility cost of search $\xi \geq 0$ for the unemployed.

Labor markets are frictional: new matches, or hires $\left(h_{i t}\right)$, between unemployed workers and vacancies in market $i$ are determined by the matching function $\phi_{i t} m\left(u_{i t}, v_{i t}\right)$, with $m$ strictly increasing and strictly concave in both arguments and homogeneous of degree one in $\left(u_{i t}, v_{i t}\right)$. Note that while the function $m$ is common across sectors and time invariant, $\phi_{i t}$ - a measure of matching efficiency (i.e., the level of fundamental frictions) in sector $i$ is allowed to vary across sector and over time. Labor productivity of a worker-firm match in sector $i$ at date $t$ is given by $z_{i t}$, and each match survives from date $t$ to $t+1$ with probability $\left(1-\delta_{t}\right)$ common across sectors. We let the laws of motion of $\phi_{t}=\left\{\phi_{i t}\right\}, \mathbf{z}_{t}=\left\{z_{i t}\right\}$, $\mathbf{v}_{t}=\left\{v_{i t}\right\}$, and $\delta_{t}$ be denoted by $\Gamma_{\boldsymbol{\phi}}\left(\phi_{t+1}, \phi_{t}\right), \Gamma_{z}\left(\mathbf{z}_{t+1}, \mathbf{z}_{t}\right), \Gamma_{\mathbf{v}}\left(\mathbf{v}_{t+1} ; \mathbf{v}_{t}\right)$, and $\Gamma_{\delta}\left(\delta_{t+1}, \delta_{t}\right)$. In SSTV we explain that (i) we can allow for an aggregate component in the dynamics of all these sectoral variables, and hence some degree of correlation among them, and that (ii) it is convenient to impose that $z_{i t}$ and $1-\delta_{t}$ are both independent martingales.

Within each period, events unfold as follows. At the beginning, $\left\{\mathbf{z}_{t}, \mathbf{v}_{t}, \boldsymbol{\phi}_{t}, \delta_{t}\right\}$ are observed. At this stage, the distribution of active matches $\mathbf{e}_{t}=\left\{e_{i t}\right\}$ across markets-and hence the total number of unemployed workers $u_{t}$-is also given. Next, unemployed workers are allocated by the planner to market $i$. Once the unemployed workers are allocated, the matching process takes place and $h_{i t}=\phi_{i t} m\left(u_{i t}, v_{i t}\right)$ new hires are generated in each market. Production occurs in the $e_{i t}$ (pre-existing) plus $h_{i t}$ (new) matches. Existing matches in sector $i$ produce $z_{i}$ units of output, but new matches produce only a fraction $\gamma<1$ of output compared to existing matches. ${ }^{4}$

\footnotetext{
${ }^{3}$ SSTV (2014) provides an extension where the assumption of exogeneity of the distribution of vacancies is relaxed. Since the presence of job-seekers in declining sectors makes it easier to fill jobs in those sectors, it distorts firms' incentives in the direction of inefficiently creating vacancies in the wrong markets. This channel depresses aggregate vacancy creation relative to the planner's solution, giving a further boost to the mismatch channel.

${ }^{4}$ This is, admittedly, a stylized way to model training costs for the newly hired which captures the idea that
} 
Next, matches are destroyed exogenously, determining the next period's employment distribution $\mathbf{e}_{t+1}$. Finally, the planner chooses the labor force for next period. Given the new labor force $\ell_{t+1}$, and the new employment stock $e_{t+1}=\sum_{i=1}^{I} e_{i, t+1}$, next-period stock of unemployed workers $u_{t+1}$ is also determined.

We now state the planner's problem in recursive form (omitting time subscripts):

$$
\begin{aligned}
V(u, \mathbf{e} ; \mathbf{z}, \mathbf{v}, \boldsymbol{\phi}, \delta) & =\max _{\left\{u_{i}\right\}_{i=1}^{I}, \ell^{\prime}} \sum_{i=1}^{I} z_{i}\left(e_{i}+\gamma h_{i}\right)-\xi u+\beta \mathbb{E}\left[V\left(u^{\prime}, \mathbf{e}^{\prime} ; \mathbf{z}^{\prime}, \mathbf{v}^{\prime}, \boldsymbol{\phi}^{\prime}, \delta\right)\right] \\
\sum_{i=1}^{I} u_{i} & \leq u \\
h_{i} & =\phi_{i} m\left(u_{i}, v_{i}\right) \\
e_{i}^{\prime} & =(1-\delta)\left(e_{i}+h_{i}\right) \\
u^{\prime} & =\ell^{\prime}-\sum_{i=1}^{I} e_{i}^{\prime} \\
u_{i} & \in[0, u], \ell^{\prime} \in[0,1], \\
\Gamma_{\mathbf{v}} & \left(\mathbf{v}^{\prime} ; \mathbf{v}\right), \Gamma_{\boldsymbol{\phi}}\left(\boldsymbol{\phi}_{t+1}, \boldsymbol{\phi}_{t}\right), \Gamma_{\mathbf{z}}\left(\mathbf{z}^{\prime} ; \mathbf{z}\right), \Gamma_{\delta}\left(\delta^{\prime}, \delta\right)
\end{aligned}
$$

In what follows we assume an interior solution for all the choice variables. The decision of how many unemployed workers $u_{i}$ to allocate in the $i$ market yields the first-order condition

$$
\gamma z_{i} \phi_{i} m_{u_{i}}\left(\frac{v_{i}}{u_{i}}\right)+\beta \mathbb{E}\left[-V_{u}^{\prime}(\cdot)+V_{e_{i}}^{\prime}(\cdot)\right](1-\delta) \phi_{i} m_{u_{i}}\left(\frac{v_{i}}{u_{i}}\right)=\mu,
$$

where $m_{u_{i}}$ is the derivative of the matching function with respect to $u_{i}$, and where $\mu$ is the multiplier on constraint (2). ${ }^{5}$ The Envelope conditions with respect to the states $u$ and $e_{i}$ yield:

$$
\begin{aligned}
V_{u}(u, \mathbf{e} ; \mathbf{z}, \mathbf{v}, \boldsymbol{\phi}, \delta) & =\mu-\xi \\
V_{e_{i}}(u, \mathbf{e} ; \mathbf{z}, \mathbf{v}, \boldsymbol{\phi}, \delta) & =z_{i}+\beta(1-\delta) \mathbb{E}\left[V_{e_{i}}^{\prime}-V_{u}^{\prime}\right] .
\end{aligned}
$$

According to the first Envelope condition, the marginal value of an unemployed to the planner equals the shadow value of being available to search $(\mu)$ net of the disutility of search $\xi$.

workers lose some of their specific skills when they separate. Ideally, this training cost would be a function of both the sector of origin and the sector of new employment. However, this extension would require keeping track of the distribution of sector of origin of job-seekers, a feature that would break the analytical tractability of the model. For a numerically-solved model along this lines, see Guvenen et al. (2015).

${ }^{5}$ In equation (8), the derivative of the sector-specific matching function $m$ is written as a function of sectoral market tightness only (with a slight abuse of notation) because of its CRS specification. 
The second condition states that the marginal value of an employed worker is its flow output this period, plus its discounted continuation value net of the value of search, conditional on the match not being destroyed.

The optimal decision on the labor force size next period $\ell^{\prime}$ requires

$$
\mathbb{E}\left[V_{u}\left(u^{\prime}, \mathbf{e}^{\prime} ; \mathbf{z}^{\prime}, \mathbf{v}^{\prime}, \boldsymbol{\phi}^{\prime}, \delta\right)\right]=0 .
$$

By combining (11) with (9), we note that the planner will choose the size of the labor force so that the expected shadow value of an unemployed worker $\mathbb{E}\left[\mu^{\prime}\right]$ equals search disutility $\xi$.

Using (11) into the Envelope condition (10), and exploiting the additional assumption that $\left(z_{i}, 1-\delta\right)$ are both independent martingales, iterating forward we arrive at:

$$
\mathbb{E}\left[V_{e_{i}}^{\prime}\right]=\frac{z_{i}}{1-\beta(1-\delta)}
$$

which, substituted into equation (8), yields

$$
\gamma z_{i} \phi_{i} m_{u_{i}}\left(\frac{v_{i}}{u_{i}}\right)+\frac{\beta(1-\delta)}{1-\beta(1-\delta)} z_{i} \phi_{i} m_{u_{i}}\left(\frac{v_{i}}{u_{i}}\right)=\mu .
$$

Rearranging, we conclude that the planner distributes idle labor to equalize

$$
z_{i} \phi_{i} \cdot m_{u_{i}}\left(\frac{v_{i}}{u_{i}^{*}}\right)
$$

across sectors, where we have used the "**" to denote the planner's allocation. This condition states that the planner allocates job seekers in order to equalize their marginal value across markets. The higher the number of vacancies $v_{i}$ and matching efficiency $\phi_{i}$, the more unemployed workers the planner wants searching in market $i$ because more hires can be generated. The higher productive efficiency $z_{i}$, the more job seekers the planner wants in that market because, if hired, they produce more output.

\subsection{Output Loss from Mismatch}

We now describe how to obtain an index that measures the fraction of output lost because of misallocation of labor supply across sectors. For the rest of the derivation, we assume that the sector specific matching function $m\left(v_{i t}, u_{i t}\right)$ is Cobb-Douglas, and $\alpha$ is its vacancy share.

To simplify the notation, we define the level of productive and matching efficiency in market $i$ at date $t$ in a compact way as $x_{i t}=z_{i t} \phi_{i t}$. Then, using (14), the optimality condition dictating how to allocate unemployed workers between market $i$ and market $j$ is:

$$
\frac{v_{j t}}{u_{j t}^{*}}=\left(\frac{x_{i t}}{x_{j t}}\right)^{\frac{1}{\alpha}} \cdot \frac{v_{i t}}{u_{i t}^{*}} .
$$


Summing across $j^{\prime} s$ allows to arrive to an expression for the share of the total number of unemployed $u_{t}$ that the planner would allocate to search in sector $i$, we obtain:

$$
\frac{u_{i t}^{*}}{u_{t}}=x_{i t}^{\frac{1}{\alpha}}\left(\frac{v_{i t}}{v_{x t}}\right)
$$

where $v_{x t}=\sum_{i=1}^{I} x_{i t}^{\frac{1}{\alpha}} v_{i t}$.

Planner's output from new hires at date $t$ equals:

$$
y_{t}^{*}=\gamma \sum_{i=1}^{I} z_{i t} h_{i t}^{*}=\gamma \sum_{i=1}^{I} x_{i t}\left(v_{i t}\right)^{\alpha}\left(u_{i t}^{*}\right)^{1-\alpha},
$$

where the second equality uses the expression for optimal hires $h_{i t}^{*}$ in each sector $i$. Rearranging, and using (15), we arrive at:

$$
y_{t}^{*}=\gamma v_{t}^{\alpha} u_{t}^{1-\alpha}\left[\sum_{i=1}^{I} x_{i t}\left(\frac{v_{i t}}{v_{t}}\right)^{\alpha}\left(\frac{x_{i}^{\frac{1}{\alpha}} v_{i t}}{v_{x t}}\right)^{1-\alpha}\right] .
$$

By solving out the term in squared brackets, we can write planner's output from the new hires more compactly as

$$
y_{t}^{*}=\gamma X_{t} \cdot v_{t}^{\alpha} u_{t}^{1-\alpha}
$$

where

$$
X_{t}=\left[\sum_{i=1}^{I} x_{i t}^{\frac{1}{\alpha}}\left(\frac{v_{i t}}{v_{t}}\right)\right]^{\alpha}
$$

is a CES aggregator of sector-specific matching and productive efficiencies, weighted by vacancy shares.

Total output from actual new hires $h_{i t}$ is given by

$$
y_{t}=\gamma \sum_{i=1}^{I} z_{i t} h_{i t}=\gamma v_{t}^{\alpha} u_{t}^{1-\alpha}\left[\sum_{i=1}^{I} x_{i t}\left(\frac{v_{i t}}{v_{t}}\right)^{\alpha}\left(\frac{u_{i t}}{u_{t}}\right)^{1-\alpha}\right]
$$

Thus, combining (16) and (17), we can define the index $\mathcal{Y}_{t}$, which measures the aggregate output loss from new hires because of job-seeker misallocation at time $t$, as

$$
\mathcal{Y}_{t}=\frac{y_{t}^{*}-y_{t}}{y_{t}^{*}}=1-\sum_{i=1}^{I}\left(\frac{x_{i t}}{X_{t}}\right)\left(\frac{v_{i t}}{v_{t}}\right)^{\alpha}\left(\frac{u_{i t}}{u_{t}}\right)^{1-\alpha} .
$$

Note that this index is written entirely as a function of observable variables. ${ }^{6}$ The index $\mathcal{Y}_{t}$ is always between zero and 1. If all unemployed are in markets with no vacancies, zero

\footnotetext{
${ }^{6}$ Moreover, this index does not depend on $\gamma$ because (i) both in the planner and in the observed allocation new hires are subject to the training cost, and (ii) the training cost is assumed to be the same across sectors.
} 
matching, or zero productive efficiency, the index is one. This is the worst possible case of misallocation. Instead, if $x_{i t}$ and $v_{i t}$ are the same in every market, there is no scope for misallocation.

\subsection{Counterfactual Output in Absence of Mismatch}

Our goal is to use the index $\mathcal{Y}_{t}$ to construct a counterfactual measure of aggregate output that would have been observed in the absence of mismatch. Actual total output in the economy is given by

$$
Y_{t}=\sum_{i=1}^{I} z_{i t} e_{i t}+y_{t}
$$

where $y_{t}$ is the output from new hires defined in (17). Similarly, counterfactual output is given by

$$
Y_{t}^{*}=\sum_{i=1}^{I} z_{i t} e_{i t}^{*}+y_{t}^{*}
$$

where $e_{i t}^{*}$ is counterfactual employment and $y_{t}^{*}$ is the counterfactual output from new hires defined in (16). Suppose we wish to analyze the effect of mismatch on aggregate output in period $t$. Then, it is enough to calculate the difference:

$$
Y_{t}^{*}-Y_{t}=\sum_{i=1}^{I} z_{i t}\left(e_{i t}^{*}-e_{i t}\right)+\frac{\mathcal{Y}_{t}}{1-\mathcal{Y}_{t}} \cdot y_{t} .
$$

The vectors $\left\{z_{i t}, e_{i t}\right\}$ can be measured directly from the data, $y_{t}$ can be computed from (17), and the output loss index can be computed from (18). Note that now $\gamma$ matters in determining this difference because it rescales the way new hires contribute to output in their first period through the term $y_{t}$ : the lower is $\gamma$, the lower will be the initial output loss from misallocation coming from newly hired workers.

The equation above suggests that there are two ways in which mismatch can dampen output growth: first, by reducing the number of aggregate hires; second, by channeling hires in the wrong sectors, those with lower productivity.

To calculate the counterfactual employment stock in each sector $i$ at date $t$, we use the following law of motion for employment: ${ }^{7}$

$$
e_{i t}^{*}=\left(1-\delta_{i, t-1}\right) e_{i, t-1}^{*}+h_{i t}^{*}
$$

\footnotetext{
${ }^{7}$ While,to simplify the exposition, we assume that the match destruction rate $\delta$ is common across sectors in the calculation of the mismatch index, we use sector-specific destruction rates, $\delta_{i}$ in computing the counterfactual employment stock to be able to match the evolution of employment over time.
} 
that we can rewrite conveniently as

$$
e_{i t}^{*}=\left(1-\delta_{i, t-1}\right) e_{i, t-1}^{*}+\frac{1}{1-\mathcal{M}_{x t}} h_{i t},
$$

where $h_{i t}=\phi_{i t}\left(v_{i t}\right)^{\alpha}\left(u_{i t}\right)^{1-\alpha}$ are actual hires and $\mathcal{M}_{x t}$ is the mismatch index derived in SSTV:

$$
\mathcal{M}_{x t}=1-\sum_{i=1}^{I}\left(\frac{\phi_{i t}}{\bar{\phi}_{x t}}\right)\left(\frac{v_{i t}}{v_{t}}\right)^{\alpha}\left(\frac{u_{i t}}{u_{t}}\right)^{1-\alpha},
$$

with

$$
\bar{\phi}_{x t}=\sum_{i=1}^{I} \phi_{i t}\left(\frac{x_{i t}}{\bar{x}_{t}}\right)^{\frac{1-\alpha}{\alpha}}\left(\frac{v_{i t}}{v_{t}}\right), \text { and } \bar{x}_{t}=\left[\sum_{i=1}^{I} x_{i t}^{\frac{1}{\alpha}}\left(\frac{v_{i t}}{v_{t}}\right)\right]^{\alpha} .
$$

Summing over employment and hires across sectors in (20) we arrive at the law of motion for counterfactual aggregate employment

$$
e_{t}^{*}=\left(1-\delta_{i, t-1}\right) e_{t-1}^{*}+\frac{1}{1-\mathcal{M}_{x t}} h_{t},
$$

To construct the counterfactual path for labor productivity, in absence of mismatch, it then suffices to compare actual labor productivity $Z_{t}=Y_{t} / e_{t}$ with counterfactual productivity $Z_{t}^{*}=Y_{t}^{*} / e_{t}^{*}$.

Finally, note that to use equation (23), one needs an assumption on the initial condition for the counterfactual aggregate employment stock at $t=0$, the first point in our sample. We will verify the robustness of our results to a range of different assumptions ranging from initial counterfactual employment and actual employment being equal, i.e., $e_{0}^{*}=e_{0}$, to initial counterfactual employment being in steady state, i.e., $e_{0}^{*}=h_{0}^{*} / \delta_{0}$.

\section{Empirical Implementation}

\subsection{Data Sources}

Our measurement exercise requires information on productivity, unemployment and vacancies across sectors of the economy. Throughout our analysis, we define a sector as an occupation and let the model period be one quarter. ${ }^{8}$ We make use of several data sources.

Productivity: We construct productivity by occupation using a combination of the Office of National Statistics (ONS) growth and productivity accounts and the quarterly Labor

\footnotetext{
${ }^{8}$ Table A1 in the Appendix lists all the 2-digit occupations used in the analysis. We use the year-2000 occupation classification. We only drop three types of occupations from the data: 97: Activities of Household as employer; 98: Undifferentiated goods- and services-producing activities of private households for own use; and 99: Activities of extra-territorial organisations and bodies.
} 
Force Survey. The ONS provides annual estimates of gross value added (GVA) for 2-digit SIC industries. ${ }^{9}$ We map these productivity estimates by industry into occupations using employment information in the Labor Force Survey. Specifically, for each 2- or 3- digit occupation, we calculate at each date $t$

$$
G V A_{o t}=\sum_{i=1}^{I} \frac{e_{i o t}}{e_{i t}} G V A_{i t}
$$

where $i$ the industry, $o$ is occupation, $G V A$ is real Gross Value Added and $e_{i o t}$ is the number of employed in industry $i$ and occupation $o$. Therefore, the value-added of an occupation is the weighted sum of the value-added of the contributing industries, where the weights are the fraction of that industry's employment in that occupation. ${ }^{10}$ We then calculate labor productivity in each occupation by dividing GVA by total employment in that occupation.

Unemployment and Vacancies: We make use of the administrative data collected by local employment agencies that are available through Nomis. ${ }^{11}$ The vacancy stocks and flows come from the Jobcentre Plus Vacancy Statistics and the unemployment counts are from the Jobseeker's Allowance Claimant Counts. ${ }^{12}$ Both the vacancy and unemployment stocks and flows are available starting in 2005 on a monthly basis. The administrative data have the advantage of being available at a regular frequency and at a disaggregated level which is ideal for the analysis of mismatch. One possible drawback of the data is its coverage. Not all vacancies are reported to the Jobcentres and not all unemployed workers qualify or choose to collect jobseekers' allowance. Thus employers and workers who do not use Jobcentres as one of their search channels are not captured by the administrative data.

The left panel of Figure 1 shows the total number of claimants together with the number of unemployed measured by the Labor Force Survey. As expected, survey-based unemployment is higher than claimant count unemployment since not all unemployed workers collect Job Seekers Allowance. The level of claimant count unemployment is about two thirds of labor force unemployment. However, the two measures are highly correlated with a correlation of 0.98 . In the right panel, we plot the Jobcentre Plus's vacancy measure against the Office of

\footnotetext{
${ }^{9}$ We use a chained-volume measure of Gross-Value Added. By using a quantity index, we avoids potential issues arising from increased price dispersion across sectors documented, for example, in Broadbent (2012).

${ }^{10}$ Since the GVA data is available annually, we use the annual average distribution of employment across industries and occupations

${ }^{11} \mathrm{https}: / /$ www.nomisweb.co.uk/Default.asp

${ }^{12}$ Pissarides (1986), Layard and Nickell (1986), Jackman and Roper (1987) all used published vacancy statistics notified to the Employment Service run by the Department of Employment for their analysis of mismatch for 1960s and 1970s. The vacancy data used in these studies can be thought of as the predecessor of the Jobcentre vacancy data. More recently, Coles and Smith (1996) and Burgess and Profit (2001) both used the Jobcentre data to estimate matching functions for TTWAs for the UK between 1985-1995.
} 


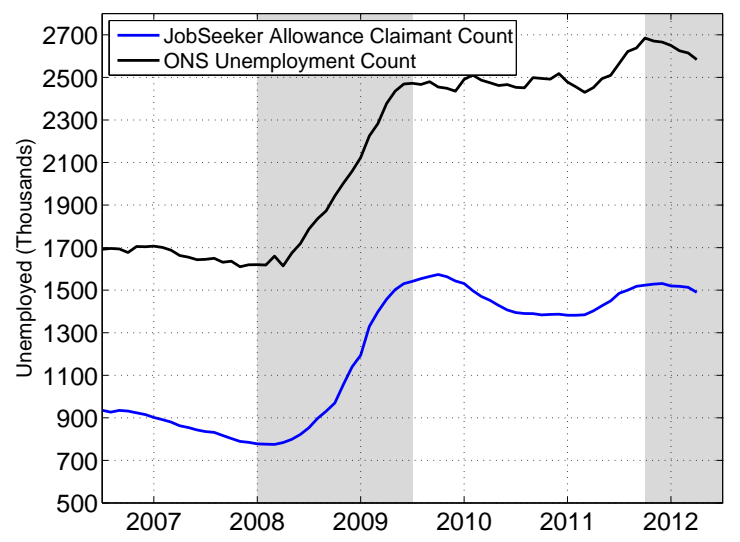

(a) Unemployed

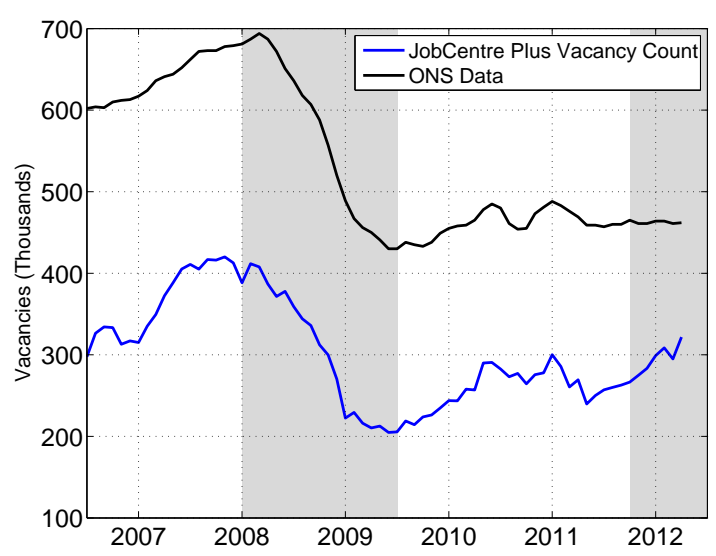

(b) Vacancies

Figure 1: Comparsion across different data sources: aggregate unemployment and vacancies in the U.K.

National Statistics' (ONS) economy-wide survey-based vacancy measure. Like our measure of the unemployed, the Jobcentre vacancy measure lies below the ONS measure. However, the two series are also highly correlated with a correlation coefficient of 0.92 .

Tables A2 and A3 in the Appendix report a breakdown of the aggregate measures along various dimensions. Table A2 shows that the administrative data sample is slightly younger than that in the Labor Force Survey and has a higher fraction of men. Before the recession, the unemployment duration distribution among the claimants was higher than in the Labor force survey. Since newly unemployed who expect to find a job easily would be less likely to claim benefits, we would expect to see more high-duration unemployed as we do in this sample. However, after the start of the recession, the duration distribution of the claimant moved down to very closely match the distribution in the labor force survey, with around $50 \%$ of both samples being unemployed for less than 6 months. As individuals likely anticipate having more difficulty finding a job during recessions, they are more likely to claim benefits and enter our sample at a lower unemployment duration. Table A3 shows that the JobCentre Plus vacancies are very highly concentrated in banking, finance, and insurance which alone represents $53 \%$ of the total number of vacancies. Compared with the survey-based measure, our sample also under-represents manufacturing, distribution, hotels and restaurants, education and health, and transportation.

In the administrative data, both unemployment and vacancy counts are available for 2-, 3-, and 4-digit occupation codes. Throughout our analysis, we focus on 2-digit and 3-digit occupation levels. For the claimant counts by occupation, we classify job-seekers using their 
sought occupation. ${ }^{13}$ We use unfilled live vacancies as our measure of stock of vacancies and the total Jobseeker claimant count as our measure of stock of unemployment. Both of these stocks are reported at the end of each month, so they are synchronized.

We start our analysis from July 2006. This choice is motivated by a change in Jobcentre Plus's vacancy handling procedure which was introduced in May 2006. In particular, prior to May 2006, vacancies notified to Jobcentre Plus were followed up with the employer to ascertain whether (a) they should remain available to jobseekers, or (b) they should be closed or had been filled by clients referred by Jobcentre Plus. Starting from May 2006 vacancies notified to Jobcentre Plus have a fixed closure date. Vacancies are automatically withdrawn on the closure date unless the employer advises that a later closure date is required. Due to this change, there is a sharp decline in the number of live unfilled vacancies in May 2006. In the final sample we use there are a few other discontinues that we take into account. ${ }^{14}$

Job Destruction and Hires: In order to construct our counterfactual employment and output as in equation (23), we need estimates of job destruction and job hires in each occupation. To be consistent and to match the evolution of employment, we calculate both job destruction rates and hires using data from the Labor Force Survey. We utilize the quarterly matched sample surveys and compute employment to unemployment and employment to non-participation transition counts. ${ }^{15}$ Specifically, we calculate:

$$
\delta_{i t}=\frac{e_{i, t-1} U_{t}+e_{i, t-1} N_{t}}{e_{i t}}
$$

This gives us the quarterly job-destruction rate for each 2 or 3 digit occupation. ${ }^{16} \mathrm{Sim}$ ilarly, we calculate hires in occupation $i$ as the sum of unemployment to employment and non-participation to employment flows

\footnotetext{
${ }^{13}$ We could also have used the usual occupation to classify claimants. The correlation between the two series is 0.99 on average across occupations. The difference in claimant counts when using the usual occupation vis-a-vis the sought occupation is, on average, less than $2 \%$ of the total stock of claimants in the occupation.

${ }^{14}$ Starting in March 2007, ONS added UK armed forces vacancies into the data under "Protective Service Occupations" (SOC $=33$ ) and "Protective Service Officers" ( $\mathrm{SOC}=117)$. This caused approximately a tenfold increase in the number of vacancies in these occupations. Also, all the UK armed forces vacancies were allocated to the "Lincoln" Travel to Work Area. To address this issue, we have excluded these occupations and geographical area from our analysis. Lastly, there was an irreconcilable spike in vacancy outflows for "administrative occupations: government and related organizations" (SOC=411) in May 2009. We impute the May 2009 value by taking the average of April 2009 and June 2009. The aggregate 2-digit occupation code (SOC=41) was also imputed for May 2009 in the same way. Lastly, the claimant and vacancy counts are missing for September 2010 so we again interpolate the September 2010 value by taking the average of August 2010 and October 2010.

${ }^{15}$ We remove the seasonal component from these flows by regressing the series on quarter dummies. Because the data is noisy, we also take a centered 3-quarter moving average series.

${ }^{16}$ Note that this measure does not include job-to-job transitions.
} 


$$
h_{i t}=U_{t-1} e_{i, t}+N_{t-1} e_{i, t} .
$$

Figure A1 in the Appendix plots the job destruction rates and hires for select occupations.

Training Costs: In the solution of the planner's problem and in our counterfactual exercises we posit that new hires produce only a fraction $\gamma<1$ of output compared to incumbent workers at a given firm. We calibrate this parameter using evidence from the Economic Organisation and Public Policy (EOPP) survey, as cited in Barron et al. (1997). They report that the EOPP survey finds that about $95 \%$ of all newly hired workers receive some kind of on-the-job training. The total average cost of training man-hours is equivalent to roughly one half of the quarterly wage per newly hired worker. With a labor share of $2 / 3$ of output, this is equivalent to about one month of output per worker. Therefore, in our exercises, we set $\gamma=0.66$ as our baseline (in other words, a newly hired worker produces two thirds of an incumbent worker's output over one quarter), but also report results for the lower bound of no output loss due to training $(\gamma=1)$, and the upper bound of training costs equivalent to two quarters' worth of output $(\gamma=-1)$.

\subsection{Matching function specification}

For the estimation of the matching function, we need a measure of total matches formed within a month. In the administrative data, we have two potential measures of hires. One potential measure is the total vacancy outflows which measures the total number of live vacancies which disappear each month. This measure would assume that all vacancies that flow out of the sample are filled by unemployed seekers. This assumption is unlikely to hold in practice given that some vacancies are filled by employed or nonparticipant workers. An alternative measure of total matches is total claimant off-flows, which measures the number of claimants who exit the sample each month. ${ }^{17}$ This measure of matches would assume that all unemployed who leave the sample do so because they find jobs. This assumption is also unlikely to hold as people can stop claiming Jobseeker benefits for various reasons other than finding a job. ${ }^{18}$ In what follows, we use the average of the two outflow series as our measure of matches. ${ }^{19}$

\footnotetext{
${ }^{17}$ This measure is similar to the unemployment outflow measure used in Shimer (2005).

${ }^{18}$ While the Jobseeker data does include information on the reason for exiting the sample, the percentage of off-flows with a "not known" or "failed to sign" destination has increased significantly since the start of the series (representing $45 \%$ of total UK off-flows in June 2012) as the completion levels of the forms filled in by Job Seekers's Allowance leavers decreased significantly over the sample period. This complicates the interpretation of the series and the decline in the job-finding rate over the recession.

${ }^{19}$ See Figure A2 in the Appendix for a plot of these alternative measures of hires, and Table A4 for the results of the matching function estimation using these alternative measures.
} 


\begin{tabular}{lcc}
\hline \hline & Estimates & Sample Size \\
\hline Aggregate & $\begin{array}{c}0.559^{* * *} \\
(0.059)\end{array}$ & 72 \\
\hline$\phi_{i}$ Fixed & $\begin{array}{r}0.472^{* * *} \\
(0.006)\end{array}$ & 1728 \\
\hline$\phi_{i}$ Varying & $\begin{array}{l}0.463^{* * *} \\
(0.010)\end{array}$ & 1728 \\
\hline
\end{tabular}

Table 1: OLS estimates of the vacancy share $\alpha$ using aggregate and 2-digit occupation panel data. S.E. in parenthesis. See Section 3.2 for details.

In Table 1, we report the estimation results of various regressions for a Cobb-Douglas matching function. ${ }^{20}$ At the aggregate level, we estimate a relationship of the form:

$$
\ln \left(\frac{h_{t}}{u_{t}}\right)=\mathrm{const}+\theta^{\prime} Q T T_{t}+\alpha \ln \left(\frac{v_{t}}{u_{t}}\right)+\epsilon_{t},
$$

where $Q T T_{t}$ is a vector of four elements for the quartic time trend. ${ }^{21}$ At the sectoral level, we estimate a panel regression of the following form:

$$
\ln \left(\frac{h_{i t}}{u_{i t}}\right)=\theta^{\prime} Q T T_{t}+\chi_{t<=3 / 08} \ln \phi_{i}^{p r e}+\chi_{t>3 / 08} \ln \phi_{i}^{p o s t}+\alpha \ln \left(\frac{v_{i t}}{u_{i t}}\right)+\epsilon_{t},
$$

where we fix the vacancy share $\alpha$ to be constant across markets and over time. We estimate this regression using our twenty-four 2-digit occupations for the period July 2006-June 2012, and report results both for the model where $\phi_{i}$ is allowed to vary across sectors and for the model where it is restricted to be the same. As Table 1 shows, the estimates for $\alpha$, the elasticity of hires with respect to vacancies, range from 0.45 to 0.56 depending on the restriction on $\phi$. We choose the value $\alpha=0.5$ which is in the middle of the range.

Table A5 reports the estimates for the sectoral matching efficiency parameters $\phi_{i}$. Higher matching efficiency may be the result of a variety of factors such as looser skill requirements or differential use of informal hiring methods that make matching workers to vacancies intrinsically easier in certain jobs. ${ }^{22}$ Because matching efficiency could fluctuate differentially across sectors over the business cycle, we estimate a pre- and post- recession $\phi_{i}$. In all our

\footnotetext{
${ }^{20} \mathrm{~A}$ matching function with unit elasticity seems to be a reasonable representation of the hiring process at the sectoral level. See Sahin, Song, Topa and Violante (2014) for a discussion.

${ }^{21}$ There was a notable drop in the measured match efficiency in the U.S. during the Great Recession as documented by various studies. We include a quartic time trend for the U.K. to capture the potential shift in aggregate matching efficiency through the recent recession similar to Sahin, Song, Topa, and Violante (2014).

${ }^{22}$ See Davis, Faberman and Haltiwanger (2013), for a discussion on the sources of heterogeneity in vacancy yields.
} 


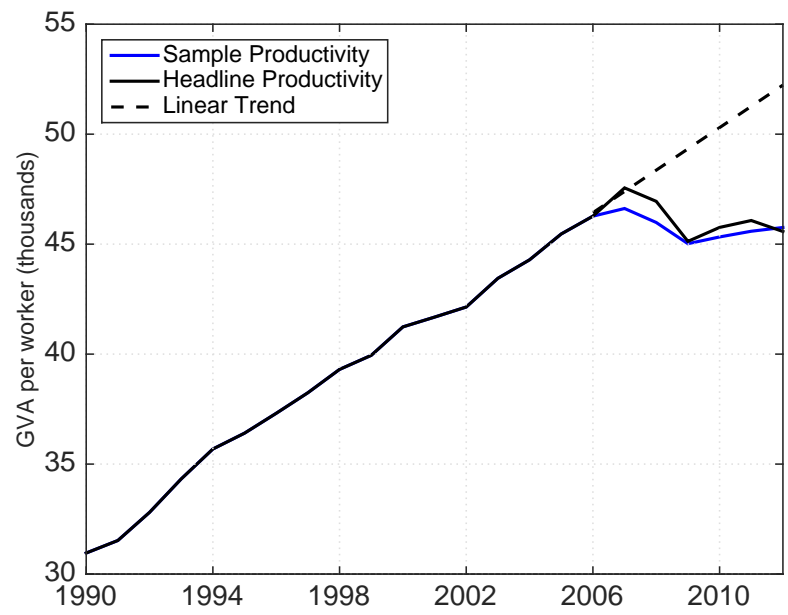

Figure 2: Aggregate UK output per worker from 1990 to 2012. See footnote 23 for definitions.

calculations, we use pre-recession estimates of sectoral matching efficiency, but our results are not sensitive to this choice.

Overall, we do not uncover a large heterogeneity in our estimates of $\phi_{i}$ 's. Secretarial (administrative), business and public sector associate, and customer service occupations have the largest $\phi_{i}$, while arts, leisure (sports), personal care, sales, and office and administrative support occupations are those with the smallest $\phi_{i}$. One interpretation of these differences is that general skill labor markets have the highest $\phi_{i}$ and specialized skill labor markets the lowest $\phi_{i}$.

\section{The Effect of Mismatch on Productivity}

Before we turn to quantifying the contribution of the misallocation channel to the decline in aggregate productivity using the theoretical framework described in Section 2, we present some initial descriptive evidence in support of this mechanism. Here we focus on 2-digit occupations to simplify the presentation, but later report our quantitative results both at the 2- and 3-digit occupation level.

\subsection{Descriptive Evidence}

Figure 2 shows the evolution of UK aggregate labor productivity from 1990 to 2012. Labor productivity rose at a roughly constant rate until 2007, at which point it dropped sharply until 2009, and remained flat thereafter. By 2012, labor productivity was still lower than at 

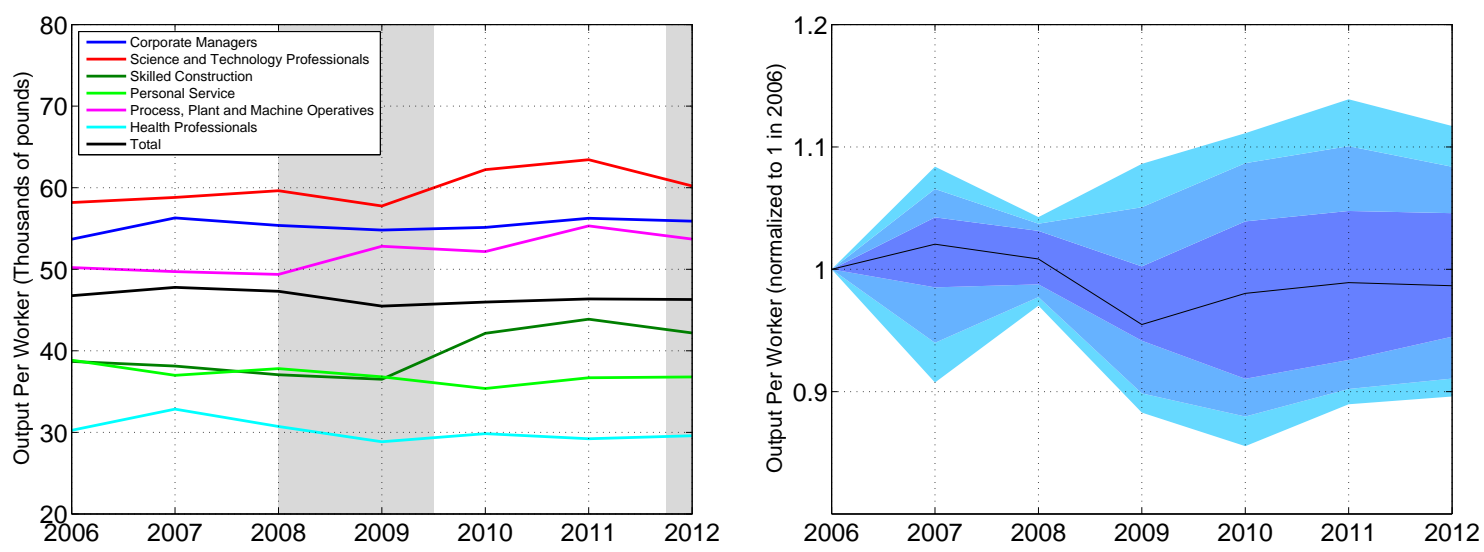

Figure 3: Left panel: output per worker for selected occupations. Right panel: productivity distribution across 2-digit occupations; the solid line represents the median and the shaded areas represent the 5th-95th, 10th-90th, and 25th-75th percentiles (lighter to darker).

its peak-a significant and persistent decline. ${ }^{23}$

As we discuss earlier, for the mismatch mechanism to be operational, it is important that there are significant differences in labor productivity across sectors. The left panel of Figure 3 shows output per worker for selected 2-digit occupations: labor productivity displays a significant amount of dispersion across occupations. Such dispersion implies that the potential for productivity losses from labor misallocation is substantial. ${ }^{24}$

Clearly, differential growth rates of productivity across sectors in addition to differences in the levels of productivity can enhance the importance of the misallocation channel. Figure 3 plots the median as well as the 5th, 10th, 25th, 75th, 90th and 95th percentiles of the productivity distribution across 2-digit occupations, and shows that there was a notable widening of the distribution after 2008. Thus, both the level differences and the increase in the dispersion of productivity across occupations suggest that the allocation of hires and employment across sectors could potentially affect the evolution of aggregate productivity.

For the allocation channel to impact overall productivity, it must be the case that actual employment growth was stronger in occupations with relatively low productivity, and vice versa. We investigate this conjecture in Table 2, which reports the correlation between the level of labor productivity over the post-recession period (2010-2012) and the change in

\footnotetext{
${ }^{23}$ The aggregate productivity measure we obtain (series "Sample Productivity") results in a slightly different series compared to the ONS counterpart computed as domestic GVA divided by total employment (series "Headline Productivity") but the discrepancy, due to the fact that we drop a few occupations in our calculation, as discussed earlier, is small.

${ }^{24}$ Table A6 in the appendix shows average output per worker for all our 2-digit occupations for the 2006-2008 and 2009-2012 periods.
} 


\begin{tabular}{cc}
\hline \hline & $z_{i}$ \\
\hline$\Delta v_{i}$ & -0.19 \\
$\Delta e_{i}$ & -0.12 \\
$\Delta e_{i}^{*}$ & 0.45 \\
\hline \hline
\end{tabular}

Table 2: The cross-occupation correlation between the level of labor productivity, $z$, over the post-recession period (2010-2012) and the change in vacancies, $v$, and actual and optimal employment, $e$, and $e^{*}$, respectively between 2010 and 2012 .

employment, vacancies, and optimal employment between 2010 and 2012. We focus on the recovery period since a big part of the productivity puzzle has to do with its persistence long after the end of the recession.

The data exhibit a negative correlation between productivity levels and vacancy and employment growth across occupations-suggesting that vacancies and employment grew more in occupations with lower levels of labor productivity. We also report the correlation between between sectoral labor productivity and the employment growth distribution chosen by the planner $\left(\Delta e_{i}^{*}\right)$. As implied by our theoretical framework, the optimal employment distribution chosen by the planner to maximize output exhibits instead a positive correlation with sectoral productivity.

Left panel of Figure 4 shows the correlation between productivity levels and employment growth over the time period under consideration. The correlation drops sharply from about 0.4 in 2007 to about -0.35 in 2009 , and only recovers slowly to about 0.08 by 2012. This is consistent with our hypothesized misallocation mechanism and suggests that employment increased in occupations with lower productivity.

Finally, the right panel of Figure 4 draws a scatter plot of productivity levels and employment growth across occupations to shed further light on the negative correlation. Employment growth was strong in many service occupations with relatively low productivity, such as health professionals, personal services, sales, or culture, media and sports. This pattern is consistent with the recent growth in employment in low-skill, but non-routine, occupations, as documented by the recent literature on job polarization (see for instance Goos et al., 2014).

The descriptive evidence presented in this section supports the view that misallocation may be an important factor in explaining the persistence of low productivity in the UK economy. However, these observations are only suggestive and do not allow us to quantify the magnitude of the impact of the misallocation channel on the overall decline in productivity. This is why we need the formal framework presented in Section 2. 

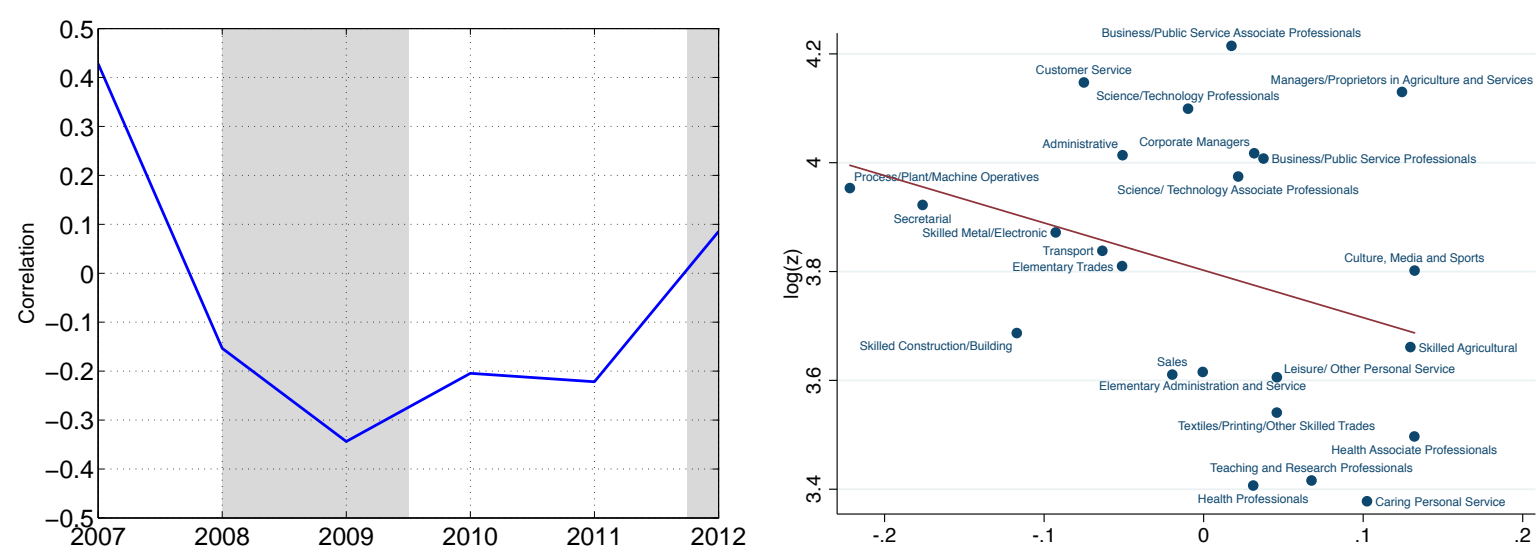

Figure 4: Left panel: correlation of productivity levels and annual employment changes across 2-digit occupations. Right panel: correlation between log change in employment and log labor productivity across 2-digit occupations over the sample period, 2006-2012.

\subsection{Quantitative Results}

In this section, we use the methodology we developed in Section 2 to quantify the importance of the mismatch channel. We focus on 3-digit occupations for our analysis, allowing us to differentiate between 76 occupations, but also report the results at the 2-digit level (24 occupations). We focus on the case with training costs equivalent to one month of lost output per worker $(\gamma=0.66)$ as our baseline, consistent with the evidence cited in Section 3.1. Finally, our baseline counterfactual results are based on starting from the actual employment rate but with the employment distribution implied by the planner's allocation. All the results are summarized in Table $3 .{ }^{25}$

We begin by presenting the hires loss index at the 3-digit occupation level in the left panel of Figure 5. Before the Great Recession, the hires loss from the misallocation of new hires was around $6 \%$ of potential new hires. At the start of the recession, this number begins a steady increase to about $14 \%$, indicating a significant increase in the misallocation of the newly employed. The right panel of Figure 5 shows the actual and the counterfactual levels of employment, with employment in the initial period (2006:Q4) normalized to 1. Counterfactual employment (in the absence of mismatch) is significantly above its empirical counterpart. While actual employment only almost got back to its pre-recession level in 2012, counterfactual employment rose about $4 \%$ above its pre-recession level, with most of

\footnotetext{
${ }^{25}$ There we also present the results with a different normalization for the initial period of the counterfactual. In particular, we start from the actual employment distribution. The choice of initial condition makes little difference in our findings.
} 


\begin{tabular}{lccc}
\hline \hline & \multicolumn{3}{c}{ Employment } \\
\hline & $e_{2012} / e_{2006}$ & $e_{2012}^{*} / e_{2006}^{*}$ & $\left(e_{2012}^{*}-e_{2012}\right) / e_{2006}$ \\
\hline 3-Digit Occupation IC1 & 1.00 & 1.05 & $5.65 \%$ \\
3-Digit Occupation IC2 & 1.00 & 1.06 & $6.26 \%$ \\
2-Digit Occupation IC1 & 1.00 & 1.03 & $2.56 \%$ \\
2-Digit Occupation IC2 & 1.00 & 1.05 & $4.75 \%$ \\
Constant z IC1 & 1.00 & 1.08 & $8.57 \%$ \\
\hline \hline & \multicolumn{4}{c}{ Output } \\
\hline & $Y_{2012} / Y_{2006}$ & $Y_{2012}^{*} / Y_{2006}^{*}\left(Y_{2012}^{*}-Y_{2012}\right) / Y_{2006}$ \\
\hline 3-Digit Occupation IC1 & 0.99 & 1.15 & $15.39 \%$ \\
3-Digit Occupation IC2 & 0.99 & 1.14 & $16.60 \%$ \\
2-Digit Occupation IC1 & 0.97 & 1.09 & $7.75 \%$ \\
2-Digit Occupation IC2 & 0.97 & 1.09 & $8.29 \%$ \\
Constant z IC1 & 0.99 & 1.07 & \\
\hline \hline & \multicolumn{4}{c}{ Productivity } \\
\hline & $Z_{2012} / Z_{2006}$ & $Z_{2012}^{*} / Z_{2006}^{*}\left(Z_{2012}^{*}-Z_{2012}\right) / Z_{2006}$ \\
\hline 3-Digit Occupation IC1 & 0.99 & 1.09 & $9.29 \%$ \\
3-Digit Occupation IC2 & 0.99 & 1.08 & $9.80 \%$ \\
2-Digit Occupation IC1 & 0.97 & 1.06 & $5.12 \%$ \\
2-Digit Occupation IC2 & 0.97 & 1.04 & $7.33 \%$ \\
Constant z IC1 & 0.99 & 0.99 & $-0.14 \%$ \\
\hline \hline
\end{tabular}

Table 3: Employment, output and productivity losses due to misallocation for different specifications. $I C 1$ and $I C 2$ differ in the assumption of the initial conditions. Results labeled as $I C 1$ are based on starting the counterfactual experiments from the actual employment rate but changing its distribution to match the one suggested by the social planner's allocation. Results labeled as $I C 2$ are based on starting from the actual employment distribution.

the gap opening after the end of the Great Recession.

What does this mean for total output? The left panel of Figure 6 shows the output loss index. The output loss from new hires shows a marked countercyclicality, suggesting that recessions are times when more severe labor mismatch induces output losses. The right panel of Figure 6 shows the actual and the counterfactual levels of output: while actual UK output was still $2 \%$ below its pre-recession level in mid-2012, in the same year counterfactual output was roughly $7 \%$ above its 2008 value.

Lastly, the left panel of Figure 7 shows the evolution of actual and the counterfactual labor productivity, $Z_{t}^{*}$ defined as $\frac{Y_{t}^{*}}{e_{t}^{*}}$. As the Figure indicates, labor productivity would be substantially higher in the absence of mismatch. Note that this result is not implied by the construction of our index. Since counterfactual hires are always higher than actual hires for any positive amount of mismatch, both counterfactual output and employment will always be higher than actual output and employment. However, labor productivity is the ratio of these 

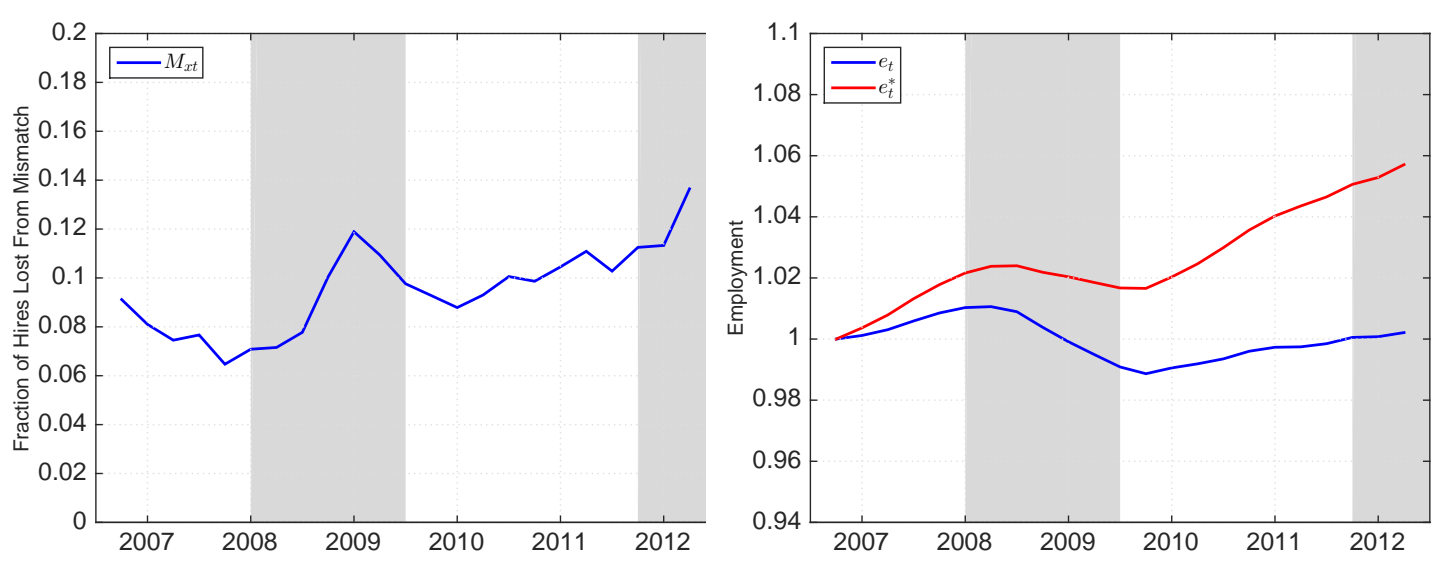

Figure 5: Left panel: mismatch index for lost hires $\left(\mathcal{M}_{t}\right)$. Right panel: the evolution of the actual employment $\left(e_{t}\right)$ and counterfactual employment $\left(e_{t}^{*}\right)$ both normalized to 1 in the initial period (2006:Q4).

two variables, and thus whether counterfactual productivity is higher (and grows faster) than its empirical counterpart is an empirical question.

The left panel of Figure 7 shows the counterfactual productivity both allowing $z_{i t}$ to vary, and holding it constant across occupations and over time. With a common $z$, both counterfactual output and employment would have been higher than their empirical counterparts, but labor productivity would be just about equal to actual labor productivity. This finding implies that the effect of mismatch on aggregate labor productivity in our counterfactual is driven entirely by the dispersion in productivity across sectors and the fact that many hires occurred in the wrong sectors, i.e., the low-productivity ones.

Table 4 reports results for the different choices of the magnitude of training costs discussed in Section 3.1. As one would expect, output and productivity losses are greatest in the case without training costs, since that choice maximizes the gap between the actual and the counterfactual allocation resulting from the solution to the planner's problem. Conversely, these gaps are smaller when the size of the adjustment cost is more significant. However, even with $\gamma=-1$, which corresponds to training costs equivalent to two quarters' worth of output, there is a nearly $3 \%$ productivity growth gap with the planner's solution.

To put our findings into perspective, we go back to historical productivity data in the UK economy, and compare the evolution of the actual and counterfactual productivity measures in the right panel of Figure 7 relative to trend productivity using annual data. There is a substantial shortfall in actual productivity relative to its trend. Specifically, the deviation of labor productivity from its projected trend in 2012 , which can be calculated as $\left(Z_{2012}^{\text {trend }}-\right.$ $\left.Z_{2012}\right) / Z_{2006}$, is about $14 \%$. In our baseline specification $\left.(\gamma=0.66)\right)$, the misallocation of 

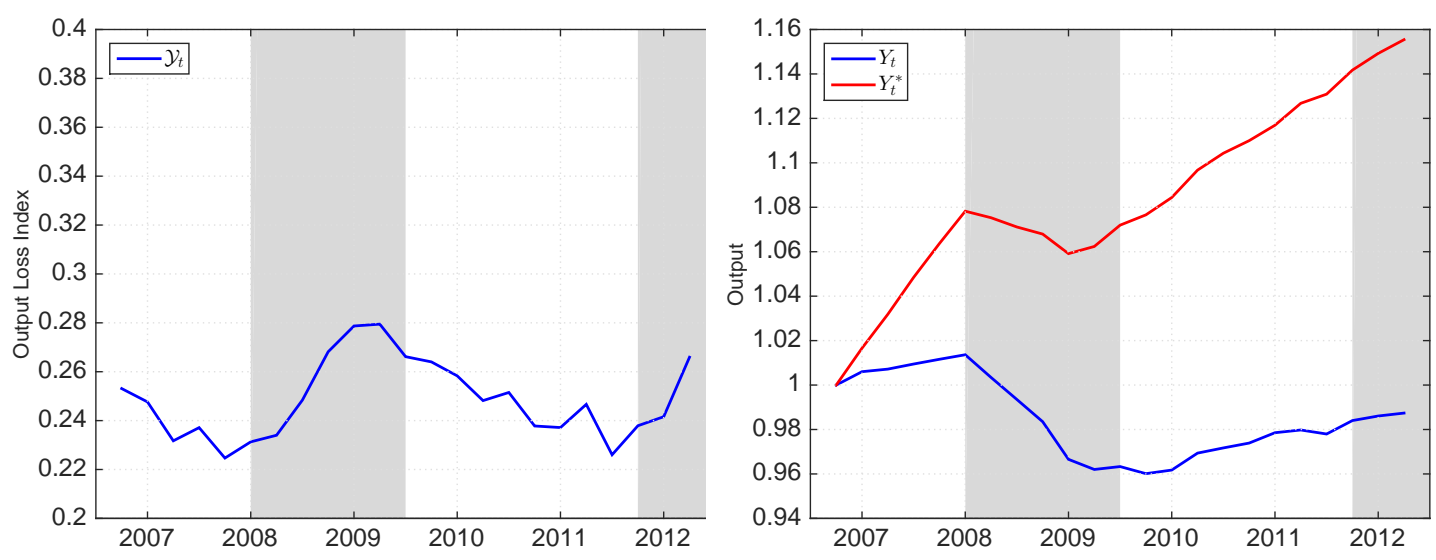

Figure 6: Left panel: mismatch index for lost output $\left(\mathcal{Y}_{t}\right)$. Right panel: the evolution of actual output $\left(Y_{t}\right)$ and counterfactual output $\left(Y_{t}^{*}\right)$ both normalized to 1 in the initial period (2006:Q4).

hires and employment across occupations explains almost two thirds of this shortfall in U.K. productivity growth since 2006. When $\gamma=1$ (no output loss due to training), misallocation across occupations explains a larger fraction of the observed drop in productivity. This is intuitive, since in this case there is no "penalty" associated to reallocating workers to different occupations, and counterfactual productivity is therefore higher in the planner's allocation. Finally, the dotted line shows that when training costs are equivalent to two quarters of output loss per worker $(\gamma=-1)$, the model explains around $20 \%$ of the observed decline in labor productivity.

\section{Conclusion}

Since the most recent recession, the UK has experienced a significant and persistent decline in output that has largely exceeded the drop in employment. As a result, labor productivity has stagnated and had not yet recovered several years after the recession. In 2012, labor productivity was around $14 \%$ below trend, a fact described as the "UK productivity puzzle." In this paper we study the contribution of a particular channel-namely, misallocation between job seekers and available jobs at the occupational level — in explaining this data pattern.

We find that occupational misallocation induced a significant reduction in both employment and output that persisted through 2012. In the absence of mismatch, both output and employment would have returned abundantly above pre-recession levels. Overall, occupational mismatch can explain about two thirds of the total deviation from trend in labor productivity observed from 2007 onwards. Thus, it seems that the misallocation between 

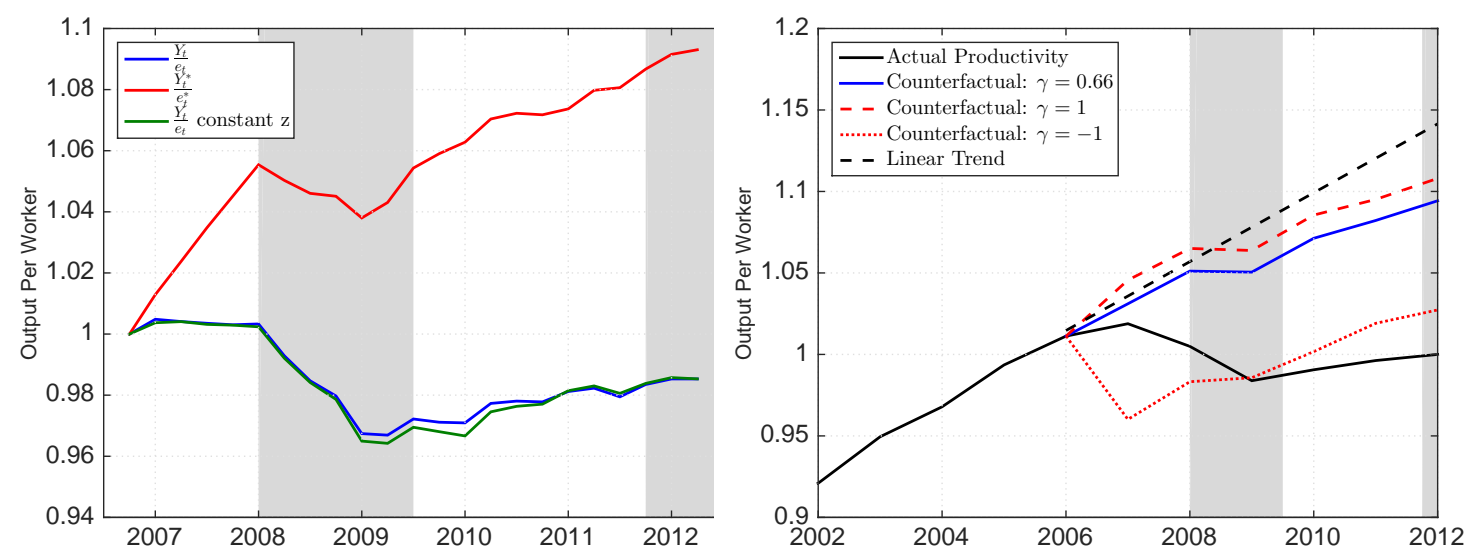

Figure 7: Left panel: actual and counterfactual aggregate labor productivity measures with and without allowing for aggregate labor productivity to vary across occupations using quarterly data, normalized to 1 in the initial period (2006:Q4). Right panel: evolution of the actual and counterfactual productivity relative to trend productivity growth for different levels of training costs using annual data, normalized to 1 in 2012.

workers and jobs across occupations that occurred during the most recent recession may have played an important role in explaining the sharp and persistent drop in productivity observed in the UK over the past decade. Investigating the reasons why job seekers were attracted by such low-productivity occupations-more so than before the recession-represents the next step of this research agenda. 


\begin{tabular}{lccc}
\hline \hline & \multicolumn{3}{c}{ Employment } \\
\hline & $e_{2012} / e_{2006}$ & $e_{2012}^{*} / e_{2006}^{*}$ & $\left(e_{2012}^{*}-e_{2012}\right) / e_{2006}$ \\
\hline 3-Digit Occupation IC1 $\gamma=0.66$ & 1.00 & 1.05 & $5.65 \%$ \\
3-Digit Occupation IC1 $\gamma=1$ & 1.00 & 1.05 & $5.65 \%$ \\
3-Digit Occupation IC1 $\gamma=-1$ & 1.00 & 1.05 & $5.65 \%$ \\
\hline \hline & $Y_{2012} / Y_{2006}$ & $Y_{2012}^{*} / Y_{2006}^{*}$ & $\left(Y_{2012}^{*}-Y_{2012}\right) / Y_{2006}$ \\
\hline & 0.99 & 1.15 & $15.39 \%$ \\
\hline 3-Digit Occupation IC1 $\gamma=0.66$ & 0.99 & 1.15 & $16.82 \%$ \\
3-Digit Occupation IC1 $\gamma=1$ & 0.99 & 1.16 & $8.41 \%$ \\
3-Digit Occupation IC1 $\gamma=-1$ & \multicolumn{3}{c}{ Productivity } \\
\hline \hline & $Z_{2012} / Z_{2006}$ & $Z_{2012}^{*} / Z_{2006}^{*}$ & $\left(Z_{2012}^{*}-Z_{2012}\right) / Z_{2006}$ \\
\hline 3-Digit Occupation IC1 $\gamma=0.66$ & 0.99 & 1.09 & $9.29 \%$ \\
3-Digit Occupation IC1 $\gamma=1$ & 0.99 & 1.09 & $10.64 \%$ \\
3-Digit Occupation IC1 $\gamma=-1$ & 0.99 & 1.10 & $2.69 \%$ \\
\hline \hline
\end{tabular}

Table 4: Employment, output and productivity losses due to labor misallocation for different specifications of training costs. $\gamma=0.66$ is our baseline specification, and corresponds to the case with training costs equivalent to one month of output per worker. $\gamma=1$ corresponds to no output loss due to training. $\gamma=-1$ corresponds to the case with training costs equivalent to two quarters' worth of output. 


\section{References}

[1] Barnett, Allna, Sandra Batten, Adrian Chiu, Jeremy Franklin and Mara Sebasti-Barriel (2014). "The UK Productivity Puzzle," Bank of England Quarterly Bulletin 2014:Q2.

[2] Barron, John M., Mark C. Berger, and Dan A. Black (1997) On-the-Job Training. W.E. Upjohn Institute for Employment Research.

[3] Broadbent, Ben (2012). "Productivity and the Allocation of Resource," Speech at the Durham Business School, September 12, 2012.

[4] Blundell, Richard, Claire Crawford, and Wenchao Jin (2014). "What Can Wages Tell Us about the UK Productivity Puzzle?," Economic Journal, vol. 124 (May), 377-407.

[5] Burgess, Simon and Stefan Profit (2001). "Externalities in the Matching of Workers and Firms in Britain,” Labour Economics, vol. 8(3), 313-333.

[6] Coles, Melvyn and Eric Smith (1996). "Cross-Section Estimation of the Matching Function: Evidence from England and Wales," Economica, 1996, vol. 63, issue 252, 589-97.

[7] Davis Steven J., R. Jason Faberman and John C. Haltiwanger (2013). "The Establishment-Level Behavior of Vacancies and Hiring," Quarterly Journal of Economics, vol. 128(2), 581-622.

[8] Goos, Maarten, Alan Manning, and Anna Salomons (2014). "Explaining Job Polarization: Routine-Biased Technological Change and Offshoring," American Economic Review, 104(8): 2509-26.

[9] Gregg, Paul, Stephen Machin, and Marina Fernandez-Salgado (2014). "Real Wages and Unemployment in the Big Squeeze," Economic Journal, vol. 124(May), 408-432.

[10] Guvenen, Fatih, Burhanettin Kuruscu, Satoshi Tanaka, and David Wiczer (2015). "Multidimensional Skill Mismatch,” NBER wp 21376.

[11] Hsieh, Chang-Tai and Peter J. Klenow (2009). "Misallocation and Manufacturing TFP in China and India," Quarterly Journal of Economics, vol. 124, 1403-1448.

[12] Jackman, Richard, and Stephen Roper (1987). "Structural Unemployment," Oxford Bulletin of Economics and Statistics, vol. 49, 9-36.

[13] Jones, Charles I. (2013). "Misallocation, Economic Growth, and Input-Output Economics," in Advances in Economics and Econometrics, Tenth World Congress, vol. II, Cambridge University Press.

[14] Layard, Richard and Stephen Nickell (1986). "Unemployment in Britain," Economica, Supplement, 53, pp. S121-S170.

[15] Midrigan, Virgiliu, and Daniel Yi Xu (2014). "Finance and Misallocation: Evidence from Plant-Level Data.” American Economic Review, vol. 104(2), 422-458.

[16] Mincer, Jacob (1966). "The Concept of Job Vacancies in a Dynamic Theory of the Labor Market," in The Measurement and Interpretation of Job Vacancies, Columbia University Press. 
[17] Moll, Benjamin (2014). "Productivity Losses from Financial Frictions: Can SelfFinancing Undo Capital Misallocation?," American Economic Review, vol. 104(10), 3186-3221.

[18] Pessoa, Joao-Paolo, and John Van Reenen (2014). "The UK Productivity Puzzle: Does the Answer Lie in Wage Flexibility?," Economic Journal, vol. 124(May), 433-452.

[19] Pissarides, Christopher (1986). "Unemployment and Vacancies in Britain," Economic Policy, 1 (3). 499-559.

[20] Restuccia, Diego and Richard Rogerson (2008). "Policy Distortions and Aggregate Productivity with Heterogeneous Plants," Review of Economic Dynamics, vol. 11, 707720.

[21] Şahin, Ayşegül, Joseph Song, Giorgio Topa, and Giovanni L. Violante (2014). "Mismatch Unemployment," American Economic Review, vol. 104(11), 3529-3564.

[22] Shimer, Robert (2005). "The Cyclical Behavior of Equilibrium Unemployment and Vacancies," American Economic Review, 95(1): 25-49. 


\section{APPENDIX Not For PUBLICATION}

\begin{tabular}{ll}
\hline \hline Code & Occupation \\
\hline 11 & Corporate Managers \\
12 & Managers and Proprietors in Agriculture and Services \\
21 & Science and Technology Professionals \\
22 & Health Professionals \\
23 & Teaching and Research Professionals \\
24 & Business and Public Service Professionals \\
31 & Science and Technology Associate Professionals \\
32 & Health and Social Welfare Associate Professionals \\
34 & Culture, Media and Sports Occupations \\
35 & Business and Public Service Associate Professionals \\
41 & Administrative Occupations \\
42 & Secretarial and Related Occupations \\
51 & Skilled Agricultural Trades \\
52 & Skilled Metal and Electronic Trades \\
53 & Skilled Construction and Building Trades \\
54 & Textiles, Printing and Other Skilled Trades \\
61 & Caring Personal Service Occupations \\
62 & Leisure and Other Personal Service Occupations \\
71 & Sales Occupations \\
72 & Customer Service Occupations \\
81 & Process, Plant and Machine Operatives \\
82 & Transport and Mobile Machine Drives and Operatives \\
91 & Elementary Trades, Plant and Storage Related Occupations \\
92 & Elementary Administration and Service Occupations \\
\hline
\end{tabular}

Table A1: 2-digit occupation codes used in our empirical analysis. 
Labor Force Survey

Claimant Count

\begin{tabular}{lcccc}
\hline & Pre-Recession & Post-Recession & Pre-Recession & Post-Recession \\
\hline \hline Age & & & & \\
$16-24$ & 0.42 & 0.39 & 0.42 & 0.35 \\
$25-49$ & 0.43 & 0.45 & 0.52 & 0.57 \\
$50+$ & 0.14 & 0.15 & 0.07 & 0.08 \\
\hline Gender & & & & \\
Male & 0.57 & 0.59 & 0.73 & 0.71 \\
Female & 0.43 & 0.41 & 0.27 & 0.29 \\
\hline Duration & & & & \\
under 6 months & 0.60 & 0.52 & 0.47 & 0.54 \\
6-12 months & 0.16 & 0.19 & 0.21 & 0.21 \\
12-24 months & 0.13 & 0.16 & 0.16 & 0.14 \\
24+ months & 0.11 & 0.13 & 0.17 & 0.12 \\
\hline \hline
\end{tabular}

Table A2: Composition of the job-seeker pool in the claimant counts data (NOMIS) and in the survey-based measures from the Labor Force Survey.

Vacancy Survey

JobCentre Plus

Pre-Recession Post-Recession Pre-Recession Post-Recession

\section{Industry}

Energy and Water

0.01

0.01

0.01

0.01

Manufacturing

0.09

0.07

0.03

0.03

Construction

0.04

0.03

0.03

0.03

Distribution, Hotels\& Restaurants

0.28

0.28

0.17

0.13

Transport and communications

0.11

0.10

0.04

0.03

Banking, Finance \& Insurance

0.23

0.21

0.57

0.53

0.21

0.24

0.12

0.20

Other Services

0.04

0.04

0.04

0.05

Table A3: Sectoral composition of vacancies in the JobCentre Plus data and in survey-based vacancy counts from the ONS. Classifications are based on aggregated 2003 SIC codes. 


\begin{tabular}{lccc}
\hline \hline & Aggregate & $\phi_{i}$ Fixed & $\phi_{i}$ Varying \\
\hline \multirow{2}{*}{ Vacancy Outflows } & $0.854^{* * *}$ & $0.813^{* * *}$ & $0.804^{* * *}$ \\
& $(0.070)$ & $(0.007)$ & $(0.014)$ \\
\hline \multirow{2}{*}{ Claimant Outflows } & $0.210^{* * *}$ & $0.076^{* * *}$ & $0.103^{* * *}$ \\
& $(0.054)$ & $(0.004)$ & $(0.007)$ \\
\hline \multirow{2}{*}{ Average Outflows } & $0.559^{* * *}$ & $0.472^{* * *}$ & $0.463^{* * *}$ \\
& $(0.060)$ & $(0.006)$ & $(0.011)$ \\
\hline
\end{tabular}

Table A4: OLS estimates of the vacancy share $\alpha$ using aggregate and 2-digit occupation panel data. S.E. in parenthesis. See Section 3.2 for details.

\begin{tabular}{lcc}
\hline \hline 2-Digit Occupation & $\phi^{\text {pre }}$ & $\phi^{\text {post }}$ \\
\hline Corporate Managers & 0.49 & 0.43 \\
Managers and Proprietors in Agriculture and Services & 0.47 & 0.41 \\
Science and Technology Professionals & 0.44 & 0.42 \\
Health Professionals & 0.56 & 0.51 \\
Teaching and Research Professionals & 0.50 & 0.48 \\
Business and Public Service Professionals & 0.50 & 0.45 \\
Science and Technology Associate Professionals & 0.46 & 0.42 \\
Health and Social Welfare Associate Professionals & 0.53 & 0.45 \\
Culture, Media and Sports Occupations & 0.43 & 0.41 \\
Business and Public Service Associate Professionals & 0.66 & 0.57 \\
Administrative Occupations & 0.55 & 0.50 \\
Secretarial and Related Occupations & 0.65 & 0.56 \\
Skilled Agricultural Trades & 0.46 & 0.47 \\
Skilled Metal and Electronic Trades & 0.48 & 0.45 \\
Skilled Construction and Building Trades & 0.51 & 0.54 \\
Textiles, Printing and Other Skilled Trades & 0.46 & 0.40 \\
Caring Personal Service Occupations & 0.43 & 0.40 \\
Leisure and Other Personal Service Occupations & 0.45 & 0.40 \\
Sales Occupations & 0.44 & 0.40 \\
Customer Service Occupations & 0.67 & 0.49 \\
Process, Plant and Machine Operatives & 0.44 & 0.42 \\
Transport and Mobile Machine Drives and Operatives & 0.44 & 0.40 \\
Elementary Trades, Plant and Storage Related Occupations & 0.50 & 0.49 \\
Elementary Administration and Service Occupations & 0.49 & 0.41 \\
\hline \hline
\end{tabular}

Table A5: Estimates of occupation-specific match efficiencies using average outflows. 


\begin{tabular}{llll}
\hline \hline & & & \\
Occupation & Occupation Code & $2006-2008$ & $2009-2012$ \\
& & 55.30 & 55.53 \\
\hline Corporate Managers & 11 & 62.04 & 62.40 \\
Managers and Proprietors in Agriculture and Services & 12 & 58.76 & 60.69 \\
Science and Technology Professionals & 21 & 31.64 & 29.56 \\
Health Professionals & 22 & 33.20 & 29.46 \\
Teaching and Research Professionals & 23 & 59.18 & 53.50 \\
Business and Public Service Professionals & 24 & 53.36 & 53.30 \\
Science and Technology Associate Professionals & 31 & 29.85 & 34.17 \\
Health and Social Welfare Associate Professionals & 32 & 46.30 & 44.29 \\
Culture, Media and Sports Occupations & 34 & 70.72 & 66.37 \\
Business and Public Service Associate Professionals & 35 & 55.84 & 55.16 \\
Administrative Occupations & 41 & 55.00 & 48.86 \\
Secretarial and Related Occupations & 42 & 40.60 & 38.37 \\
Skilled Agricultural Trades & 51 & 46.51 & 48.60 \\
Skilled Metal and Electronic Trades & 52 & 38.11 & 40.74 \\
Skilled Construction and Building Trades & 53 & 35.90 & 33.80 \\
Textiles, Printing and Other Skilled Trades & 54 & 29.81 & 29.14 \\
Caring Personal Service Occupations & 61 & 37.73 & 36.62 \\
Leisure and Other Personal Service Occupations & 62 & 37.79 & 36.38 \\
Sales Occupations & 71 & 63.56 & 63.62 \\
Customer Service Occupations & 72 & 49.80 & 53.00 \\
Process, Plant and Machine Operatives & 81 & 48.61 & 45.60 \\
Transport and Mobile Machine Drivers and Operatives & 82 & 46.42 & 44.58 \\
Elementary Trades, Plant and Storage Related Occupations & 91 & 39.65 & 36.43 \\
Elementary Administration and Service Occupations & 92 & & \\
\hline \hline
\end{tabular}

Table A6: Output per worker for 2-digit occupations for the 2006-2008 and 2009-2012 periods. 

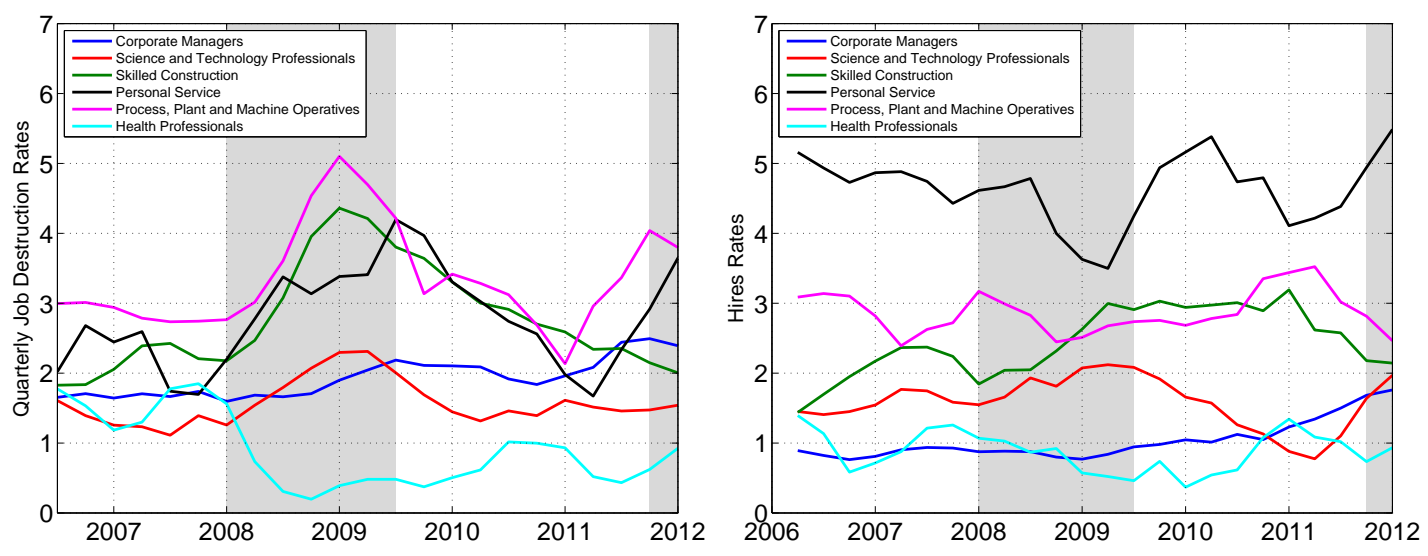

Figure A1: Job destruction rates (left) and hires rates (right) for selected occupations

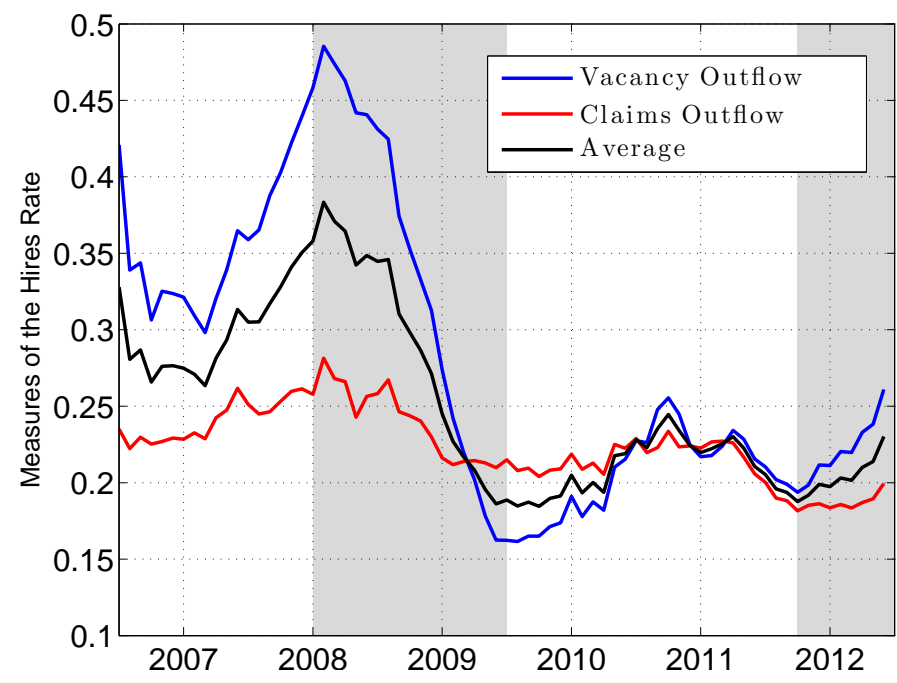

Figure A2: Time series of various measures of matches. 


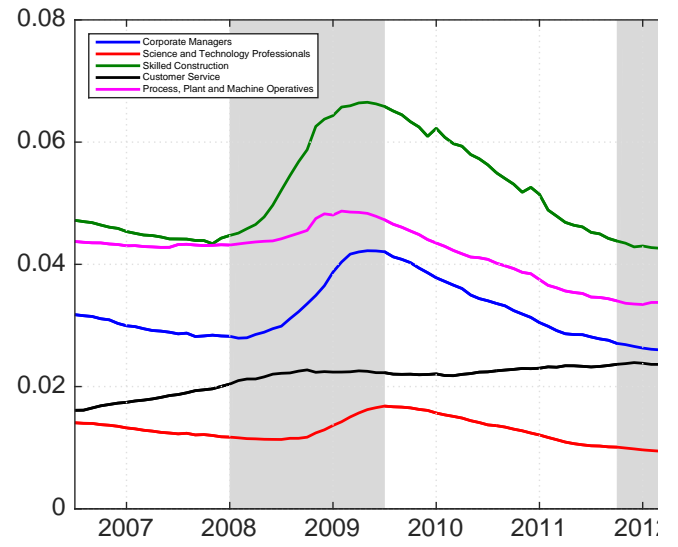

(a) Unemployment Shares

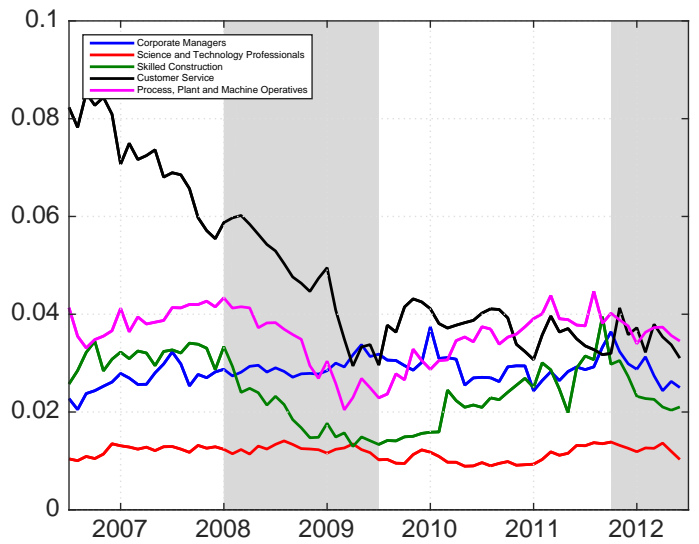

(b) Vacancy Shares

Figure A3: Unemployment and Vacancy Shares for selected occupations.

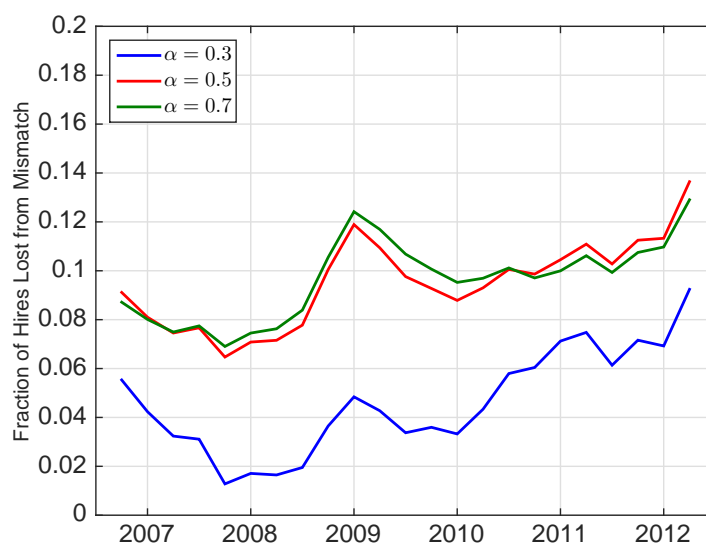

(a) Unemployment Index

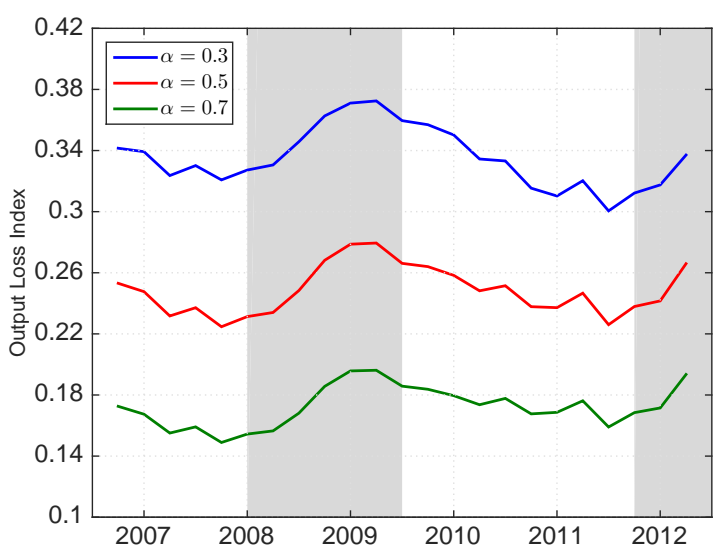

(b) Output Index

Figure A4: Mismatch index for lost hires (left) and Mismatch index for lost output (right) for different values of $\alpha$. 